\title{
Raça em formação de galinhas de plumagem azul e ovos azuis
}

\section{TESTE DE CRUZAMENTO}

E. A. GRANER e A. P. TORRES

Escola Superior de Agricultura "Luiz de Queiroz" Universidade de São Paulo
INDICE
1) Introdução $\ldots \ldots \ldots \ldots \ldots \ldots \ldots \ldots \ldots \ldots \ldots, 24$
2) Material e Método ................... 24
3) Resultados $\ldots \ldots \ldots \ldots \ldots \ldots \ldots \ldots \ldots \ldots \ldots \ldots, 24$

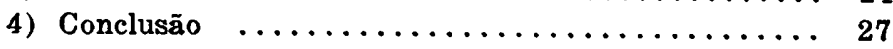
5) Abstract $\ldots \ldots \ldots \ldots \ldots \ldots \ldots \ldots \ldots \ldots \ldots \ldots, 28$
6) Bibliografia $\ldots \ldots \ldots \ldots \ldots \ldots \ldots \ldots \ldots \ldots \ldots, 28$

Trabalho da Seção de Avicultura 


\section{1 - INTRODUÇÃO}

Conforme nossa publicação anterior (2), estamos interessados na formação de uma raça de galinhas de plumagem azul e ovos azuis, partindo de material proveniente de Goiás, provavelmente das margens do Rio Araguaya e supondo tratarse de galinhas ainda não submetidas a um trabalho de domesticação. A hereditariedade da coloração da plumagem e da coloração dos ovos foi então analisada e a plumagem azul pareceu regulada por um par de alelos, de cuja interação fisiológica resultam galinhas de plumagem preta, galinhas de plumagem branco-manchada e galinhas de plumagem azul. Afim de verificar a hipótese então formulada, alguns cruzamentos entre as aves obtidas da segregação analisada foram planejados e os dados conseguidos passam a ser o motivo da presente publicação.

\section{2 - MATERIAL E MÉTODO}

Do material proveniente da segregação obtida nos cruzamentos anteriores, selecionámos galinhas de plumagem branco-manchada, de plumagem preta e de plumagem azul, as quais foram acasaladas com um galo irmão, de plumagem branco-manchada. O acasalamento foi feito em parque de reprodução e os ovos coletados e incubados separadamente para cada galinha. As demais galinhas de plumagem azul foram conservadas e acasaladas com galos também azuis. As galinhas e galos de plumagem preta foram cedidos a Granja da Usina Monte Alegre, onde tivemos o ensejo de observar a sua rəprodução.

\section{3 - RESULTADOS}

Os resultados dos cruzamentos relatados em nosso trabalho anterior (2) indicam a segregação para um par de alelos, 
designado $G g$, de cuja interação resultam galinhas GG (branco-manchadas), $G g$ (azuis) e $g g$ (pretas). O cruzamento das galinhas azuis (Ns. 21, 54, 346 e 348) com o galo branco-manchado, conforme os dados contidos no quadro n. 1, mostram, para os pintos obtidos, a segregação correspondente a uma retrocruza, isto é, $1 / 2 \mathrm{azul}: 1 / 2 \mathrm{branca}$. Os valores observados concordam com os valores esperados na base de $G g \times G G=1 / 2 G G$ (brancas) : $1 / 2 \mathrm{Gg}$ (azuis), com os respectivos valores de $x^{2}$ 0,$68 ; 2,34 ; 0,02$ e 0,02 . O total de $x^{2}$, para as galinhas referidas, é igual a 3,06, com probabilidade maior que $50 \%$. O cruzamento correspondente à retrocruza $G g \times g g$ foi já relatado no trabalho anterior (2). Duas galinhas branco-manchadas, ns. 331 e 332 (quadro n. 1), quando cruzadas com galo brancomanchado, deram todos os pintos brancos, confirmando o esperado de acôrdo com o cruzamento GG x GG. Cinco pintos de coloração azul dados como pertencendo a êstes cruzamentos podem ser postos de lado, uma vez que não podemos eliminar a possibilidade de mistura de alguns ovos, embora o contrôle seja tão rigoroso quanto possível. As galinhas pretas ns. 94, 121, 159 e 329, (quadro n. 1), quando cruzadas com o galo branco-manchado, deram sempre filhos azuis, de conformidade com o esperado na base de $G G \times g g=G g$. Os poucos pintos brancos indicados como resultantes dêstes cruzamentos devem ser também o resultado de troca realizada quando da numeração dos ovos, nos ninhos alcapão. Do cruzamento de galinhas e galos todos pretos, realizado na Granja da Usina Monte Alegre, resultaram sempre pintos pretos, segundo o cruzamento $g g \times g g$. As galinhas azuis, num total de 32, (quadro n. 2), foram reunidas em 3 parques com 3 galos azuis e deram uma descendência de pintos formada de $1 / 4$ preta: $2 / 4$ azul : $1 / 4$ branca, de conformidade com o cruzamento $\mathrm{Gg} \times \mathrm{Gg}$.

Conforme se verifica pelos resultados dos cruzamentos analisados no presente trabalho, a hipótese da segregação de um par de alelos, como responsável pelos três tipos de plumagem, no material em estudo, parece confirmar-se nestas observações. 


\section{QUADRO 1}

\begin{tabular}{|c|c|c|c|c|c|}
\hline \multirow{2}{*}{$\begin{array}{c}\text { N. da } \\
\text { galinha }\end{array}$} & \multirow{2}{*}{$\begin{array}{l}\text { Coloração } \\
\text { da galinha }\end{array}$} & \multicolumn{3}{|c|}{ Coloração dos pintos } & \multirow{2}{*}{ 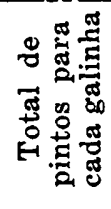 } \\
\hline & & Preta & Azul & Branca & \\
\hline 21 & Azul & 0 & 16 & 21 & 37 \\
\hline 54 & Azul & 0 & 35 & 49 & 84 \\
\hline 346 & Azul & 0 & 21 & 20 & 41 \\
\hline 348 & Azul & 0 & 18 & 19 & 37 \\
\hline Total & Azul & 0 & 90 & 109 & 199 \\
\hline 331 & Branco-manchada & 0 & 2 & 54 & 56 \\
\hline 332 & Branco-manchada & 0 & 3 & 41 & 44 \\
\hline Total & Branco-manchada & 0 & 5 & 95 & 100 \\
\hline 94 & Preta & 0 & 39 & 2 & 41 \\
\hline 121 & Preta & 0 & 71 & 1 & 72 \\
\hline 159 & Preta & 0 & 22 & 2 & 24 \\
\hline 329 & Preta & 0 & 34 & 1 & 35 \\
\hline Total & Preta & 0 & 166 & 6 & 172 \\
\hline
\end{tabular}


QUADRO 2.

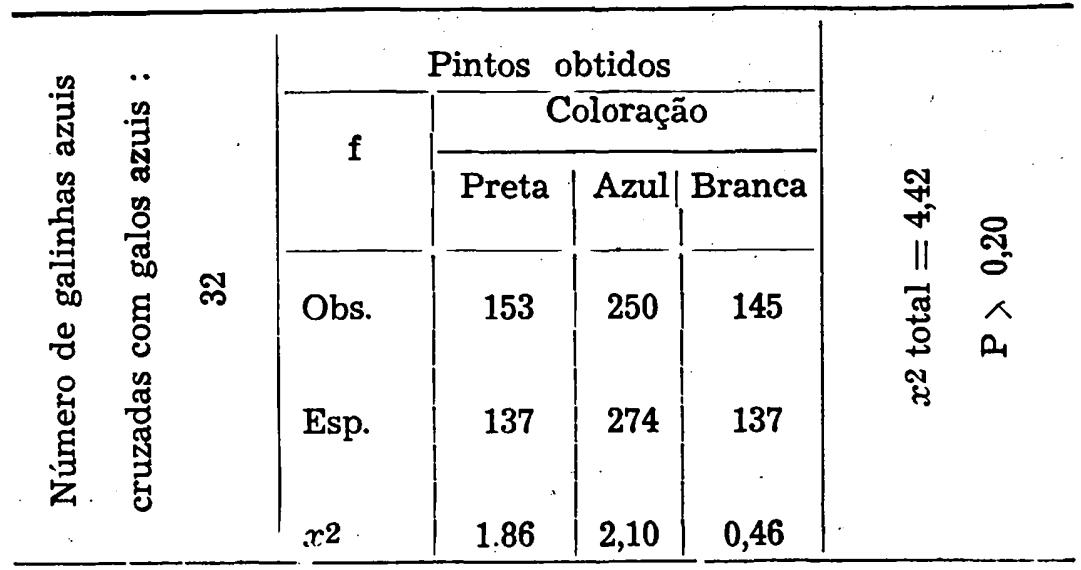

\section{4 - CONCLUSÃO}

A interação fisiológica de um par de alelos, como responsável por três tipos de plumagem (preta, azul e branco-manchada) em galinhas que botam ovos azuis, provenientes do Estado de Goiás, foi confirmada pelos cruzamentos relatados no presente trabalho. Esse par de alelos foi designado $G g$, mesmo símbolo usado por outros autores, $(G G=$ branco-manchado, $G g=$ azul e $g g=$ preta) pois parece provável tratar-se do mesmo fator genético já encontrado e analisado em outras raças, cujos resultados são pràticamente equivalentes àqueles obtidos com o presente material. A plumagem preta é relativamente uniforme, enquanto que as plumagens azul e branco-manchada apresentam certa variação. As galinhas azuis podem ter uma plumagem azul uniformemente distribuida por todo corpo, mais clara ou mais escura em diferentes galinhas, como podem ter também uma plumagem azul pouco ou regularmente salpicada de preto, seja em determinada parte, como por exemplo, no pescoço, ou então em tôda a extensão do corpo. A ação de outros fatôres genéticos assim constatada, seja atuando apenas como modificadores ou então como fatôres principais, deverá ser analisada para constatação das causas das variações observadas. 


\section{5 - ABSTRACT}

The data reported in this paper are in accordance with the hypothesis previously established (2) of the interaction of a main pair of alleles as controlling the inheritance of black, blue and blue-splashed plumage in chickens received from the State of Goias, Brazil. The black plumage is relatively uniform but the blue and blue splashed plumages indicate the action of other genes regulating the lack of uniformity.

\section{6 - BIBLIOGRAFIA}

1-CARD, L. E. and E. ROBERTS (1935). Fowls with Blue Plumage from Leghorn Cornish Cross. Poultry Science $14: 45$.

2-GRANER, E. A. e A. P. TORRES (1949). Raça em Formação de Galinhas de Plumagem Azul e Ovos Azuis. Anais da Escola Superior de Agricultura "Luiz de Queiroz" (em impressão).

3-JAAP, R. G. and T. T. MILBY (1944). Comparative Genetics of Blue Plumage in Poultry. Poultry Science 23:3-8.

4-JULL, M. A. (1940). Poultry Breeding. John Wiley \& Sons Inc., London.

5-LIPPINCOTT, W. A. (1918). The Case of the Blue Andalusian. American Naturalist 52 : 95-115.

6-LIPPINCOTT, W. A. (1921). Further Data on the Inheritance of Blue in Poultry. American Naturalist 55 : 289-327.

7-LIPPINCOTT, W. A. (1923). Genes for the Extension of Black Pigment in the Chicken. American Naturalist 57 : 284-287. 


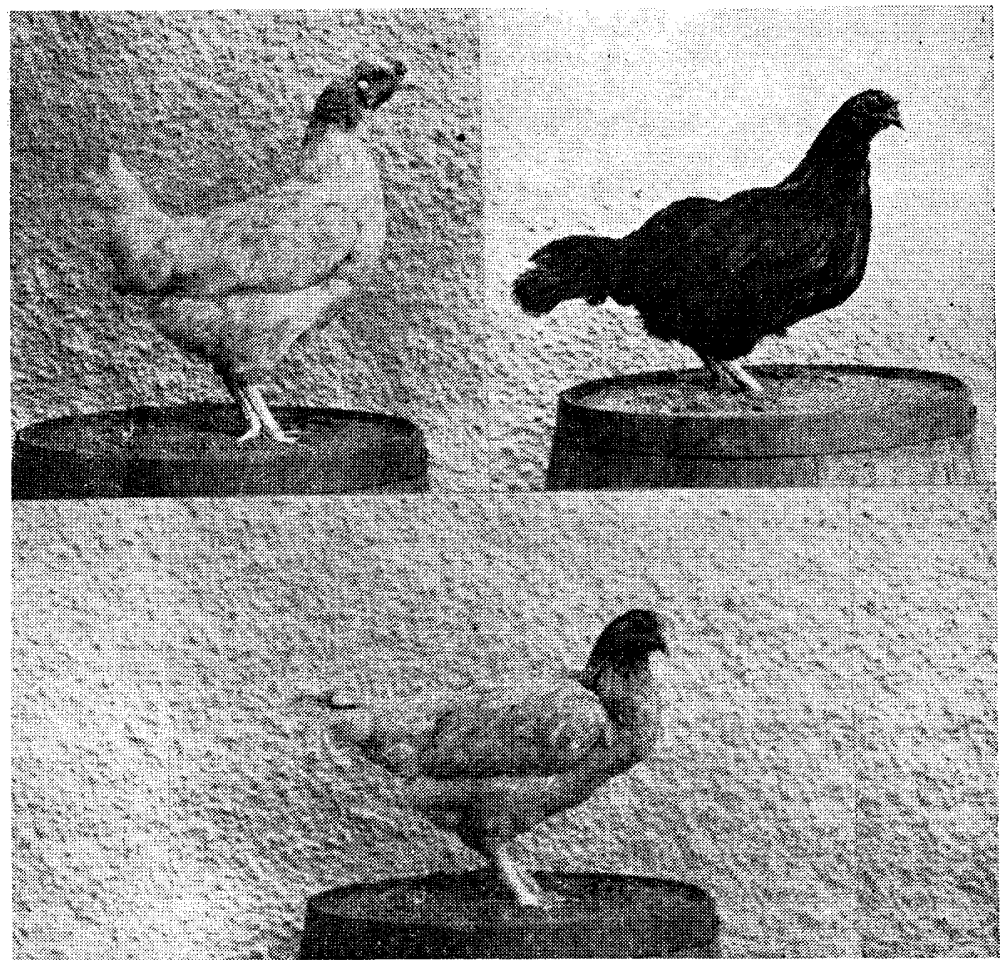

Fig. 1

Em cima : a esquerda, galinha Branco-manchada; a direita, galinha Preta

Em baixo : galinha Azul 


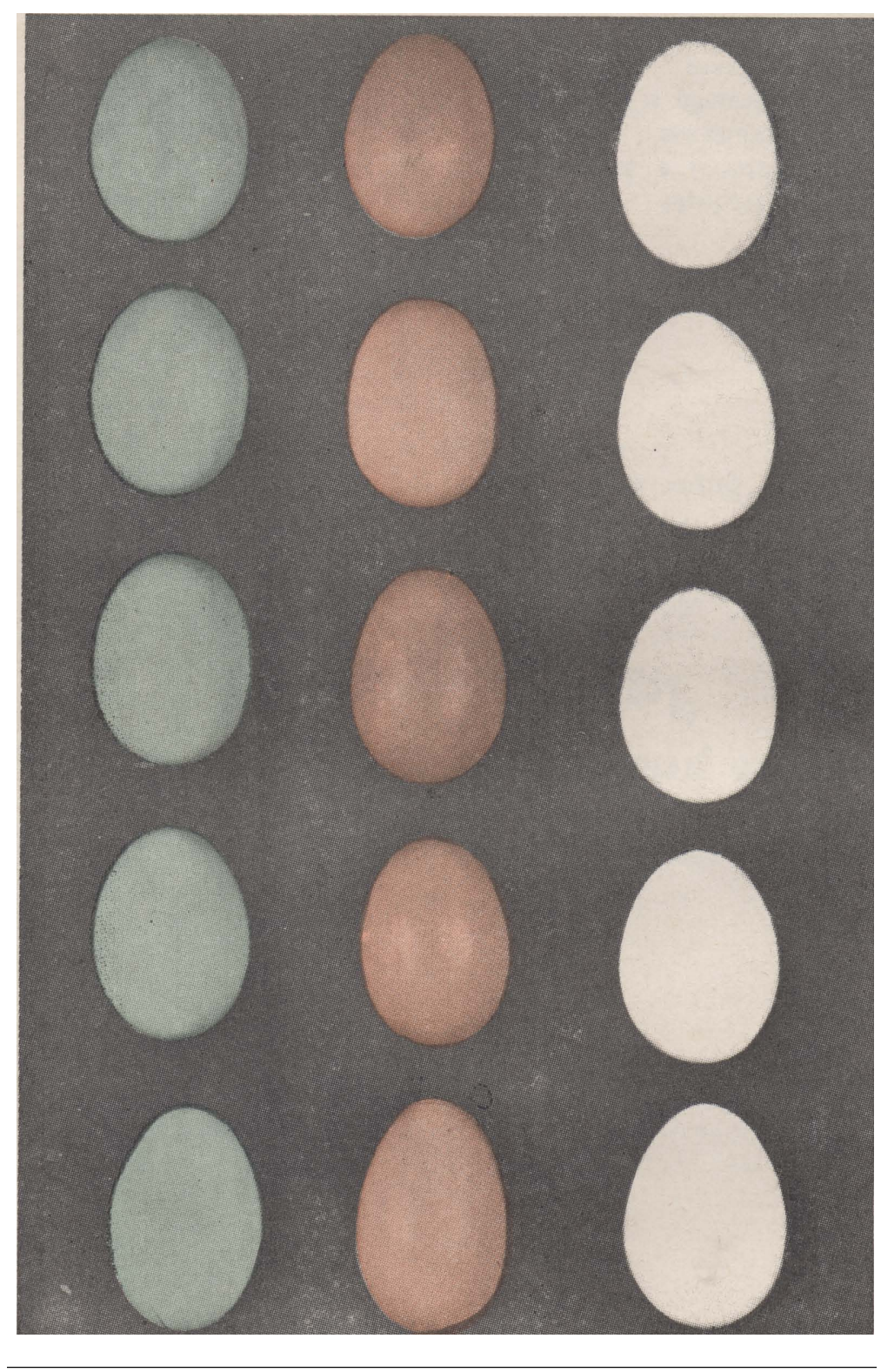

Fig. 2

A esquerda : Ovos da raça Leghorn; No centro : Ovos da raça Rhode Island Red; A direita : Ovos da raça em formação, estudada no presente trabalho 